\title{
Organocatalytic Regioselective Synthesis of Sulfur-Containing N-Alkyl Carbamates from Alkyne-Derived Cyclic Carbonates
}

\author{
Bin Liu and Xinghong Zhang* \\ MOE Key Laboratory of Macromolecular Synthesis and Functionalization, Department of Polymer Science \& \\ Engineering, Zhejiang University, 38 Zheda Road, Hangzhou, Zhejiang 310027, China \\ Email: xhzhang@zju.edu.cn (X. Z.)
}

\begin{abstract}
A highly regioselective synthesis of sulfur-containing $\mathrm{N}$-alkyl carbamate from propargyl alcohol, carbon dioxide $\left(\mathrm{CO}_{2}\right)$ and amine via metal-free catalysis is described. The regioselective ring-opening addition of tri-substituted cyclic carbonate with amine was investigated in detail. A key feature of this system is the ability to afford tertiary $\beta$-hydroxyl $N$-alkyl carbamate with $100 \%$ selectivity by using 1,5,7-triazabicyclo[4.4.0]dec-5-ene (TBD) as the catalyst in a wide range of reaction temperatures. The steric hindrance of amine and the use of ethanol favored the regioselective ring-opening addition reaction. A proposed mechanism for the ring-opening addition elaborated the underlying reason for the regioselective synthesis of sulfur-containing $\mathrm{N}$-alkyl carbamate. This study provides a new alternative synthetic route to sulfur-containing $N$-alkyl carbamates from alkyne and $\mathrm{CO}_{2}$ and may offer an attractive scaffold for further synthesis.
\end{abstract}

Keywords organocatalyst, sulfur-containing $\mathrm{N}$-alkyl carbamate, tri-substituted cyclic carbonate, regioselective ring-opening, 1,5,7-triazabicyclo[4.4.0]dec-5-ene

\section{Introduction}

It is of great significance to utilize alkyne as a synthon because alkyne can be produced from coal or calcium carbide that is very rich in nature. Indeed, alkyne and its derivatives represent one of the most fundamental building blocks for organic synthesis. ${ }^{[1-3]}$ Concurrently, carbon dioxide $\left(\mathrm{CO}_{2}\right)$, as a safe, cheap, plentiful, renewable, environmentally benign and nontoxic one-carbon (C1) resource, has already been transformed efficiently into various fine chemicals ${ }^{[4,5]}$ and polymers. ${ }^{[6]}$ Consequently, it is promising to combine alkyne or its derivatives with $\mathrm{CO}_{2}$ to produce useful compounds and materials, which can also reduce the $\mathrm{CO}_{2}$ emission and our dependency on the petroleum resources. ${ }^{[7,8]}$

As an inert $\mathrm{C} 1$ compound, $\mathrm{CO}_{2}$ is usually converted to the five-membered cyclic carbonate via the coupling reaction with alkyne derivatives or epoxides that are high-energy compounds. $^{[9-12]}$ Followed by ring-opening addition reaction with amines, these cyclic carbonates can be effectively converted to the urethane compounds. This reaction is the basic chemistry of the non-isocyanate route for making polyurethanes (PUs). ${ }^{[13,14]}$ Compared with the traditional isocyanate route, the ring-opening addition of cyclic carbonate with amines avoids the use of toxic di- or polyisocyanates that are originated from toxic phosgene. ${ }^{[15,16]}$ The coupling reaction of $\mathrm{CO}_{2}$ with various epoxides has been extensively studied for producing cyclic carbonates. ${ }^{[17-19]}$ However, most of the epoxides are derived from raw oils and often high-cost. Moreover, because of non-regioselective reaction of the cyclic carbonate with amine, two isomeric products are often produced, which caused the difficulty of separation and further preparation for well-defined PUs. ${ }^{[20-24]}$ The main reason is that the epoxide-derived cyclic carbonates are often mono- or di-substituted and less steric.
In addition, sulfur is a widely distributed element in the earth and was of tremendous importance to the development of chemistry and organic synthesis, such as the vulcanization of rubber and thiol-ene click reaction. Lots of sulfur-containing compounds are widely employed in various branches of industry because of their specific properties, i.e., high refractive indices, thermal and flame resistance, strong adhesion to various materials, etc. ${ }^{[25-27]}$ Therefore, the introduction of sulfur can improve the properties of small molecules or polymers.

Herein, we report the synthesis and regioselective ringopening reaction of a sulfur-containing five-membered cyclic carbonate using 4,4-dimethyl-5-methylene-2-oxo-1,3-dioxolane (DMOD) as the starting material. DMOD can be synthesized from the coupling reaction of $\mathrm{CO}_{2}$ and propargyl alcohol, which is an inexpensive acetylene derivative, by using various catalytic systems such as metal, ${ }^{[28-30]}$ metal complexes ${ }^{[31,32]}$, Lewis base ${ }^{[33]}$ and phosphines. ${ }^{[34,35]}$ Note that propargyl alcohol can be synthesized from the addition of acetylene and acetone, ${ }^{[36,37]}$ and acetone can also be prepared from the direct reaction of acetylene with water. ${ }^{[38]}$ Therefore, DMOD can be regarded as the product of the reaction of $\mathrm{CO}_{2}$, acetylene and water, without loss of any atom. It is thus a non-petroleum approach for making new chemicals. Previously investigations ${ }^{[39,37,40]}$ on the reaction of DMOD with amines disclosed that the intermolecular cyclization to produce oxazolidones depended on whether the catalyst exists and the types of catalysts and amines. Detrembleur et al. ${ }^{[41]}$ confirmed that the cyclization occurred quickly in the absence of catalyst. We thus considered that the modification of the double bond of DMOD could not only prevent the abovementioned cyclization, but also increase the steric hindrance that might be beneficial to the regioselective reaction, as shown in Scheme 1. Such proposed synthetic route to produce $\mathrm{N}$-substituted carbamates with sulfur element has yet not been reported. During our 


\section{Report}

preliminary studies, Kleij et al. ${ }^{[42]}$ presented an elegant study demonstrating a highly regioselective catalytic route towards carbamates from di-substituted cyclic carbonates with amine. Thereof, the cyclic carbonate was originated from 4,4-dimethyl epoxide. ${ }^{[42]}$

Scheme 1 The synthetic route of the tertiary $\beta$-hydroxyl $\mathrm{N}$-alkyl carbamates via the ring-opening addition of tri-substituted cyclic carbonates with amines by using organocatalyst. ${ }^{a}$

Organocatalytic

${ }^{a} R_{1}$ and $R_{2}$ refer to alkyl chains.

In present work, we provided a new alternative pathway to synthesize sulfur-containing carbamates derived from alkyne and $\mathrm{CO}_{2}$. A regioselective ring-opening addition of substituted DMOD with amines to access tertiary $\beta$-hydroxyl $N$-alkyl carbamate (A) with $100 \%$ selectivity via metalfree catalytic route is presented and discussed (Scheme 1).

\section{Experimental}

\section{Materials and methods}

1,5,7-Triazabicyclo[4.4.0]dec-5-ene (TBD) (98\%), 1,8diazabicyclo[5.4.0]-undec-7-ene (DBU) (99\%), 4-dimethylaminopyridine (DMAP) (99\%), butylamine (99.5\%), methyl thioglycolate (95\%), 3-mercaptopropionic acid (99\%), 1,2-ethanedithiol (98\%), 1,6-hexanedithiol (97\%), 4-methylpiperidine (99\%) and 2-methyl-3-butyn-2-ol (98\%) were purchased from Aldrich and used as received. Phosphine (95\%), 1-propanethiol (99.5\%), 2,2-dimethoxy-2-phenylacetophenone (DMPA) (99\%), cetyltrimethyl ammonium bromide (CTAB) (98\%, Aladdin), ethanol (99.8\%), chloroform $(99.8 \%)$, dodecylamine (1) (99\%), ethanolamine (2) (99\%), ethylenediamine (3) (99\%), 1,6-hexane-diamine (4) (99\%), isophorondiamine (5) (99\%), 1,2-diaminocyclohexane (6) (99\%), tris(2-aminoethyl)amine (7) (97\%), furfurylamine (8) (99\%), p-xylylenediamine (9) (99\%), aniline (10) (99\%), acetoguanamine (11) (98\%), 4-methylpiperidine (12) (99\%), 4-hydroxypiperidine (13) (98\%), 2-(methylamino)ethanol (14) (99\%) and piperazine (15) (99\%) were purchased from Aladdin and used as received.

${ }^{1} \mathrm{H}$ NMR, ${ }^{13} \mathrm{C}$ NMR and ${ }^{13} \mathrm{C}$-DEPT 135 NMR spectra of all the products were obtained on a Bruker Advance DMX $400 \mathrm{MHz}$ and $101 \mathrm{MHz}$ spectrometer using TMS as the internal reference, respectively. Infrared spectrum was measured using a Brucker Vector 22 FT-IR spectrophotometer. GC-MS spectra were taken on a GC/MS-QP2010 chromatograph.

\section{Synthesis of 4,4-dimethyl-5-methylene-2-oxo-1,3-dioxol- ane (DMOD)}

The reaction of 2-methyl-3-butyn-2-ol and $\mathrm{CO}_{2}$ was performed in the autoclave $(80 \mathrm{~mL})$ equipped with mechanical stirrer and barometer. 2-Methyl-3-butyn-2-ol (20 $\mathrm{mL}, 205.8 \mathrm{mmol})$ and phosphine $(4.2 \mathrm{~mL}, 16.8 \mathrm{mmol})$ were transferred into the autoclave. Then the autoclave was filled with $\mathrm{CO}_{2}$ until its pressure up to $3.0 \mathrm{MPa}$ under stir- ring. The pressure and temperature were kept at 5.0 MPa and $100{ }^{\circ} \mathrm{C}$, respectively, and stirred for $8 \mathrm{~h}$. Afterwards, the autoclave was cooled in an ice-water bath and the pressure was slowly vented. The resulting crude product was purified by vacuum distillation at $120{ }^{\circ} \mathrm{C}$. Yield $90 \%$. ${ }^{1} \mathrm{H} \mathrm{NMR}\left(400 \mathrm{MHz}, \mathrm{CDCl}_{3}\right) \delta: 4.76(\mathrm{~d}, J=3.9 \mathrm{~Hz}, 1 \mathrm{H}), 4.31$ $(\mathrm{d}, J=4.0 \mathrm{~Hz}, 1 \mathrm{H}), 1.61(\mathrm{~s}, 6 \mathrm{H}) ;{ }^{13} \mathrm{C}$ NMR $(101 \mathrm{MHz}$, $\left.\mathrm{CDCl}_{3}\right) \delta:$ 158.66, 151.22, 85.28, 84.68, 27.47.

\section{Synthesis of 4,4-dimethyl-5-[(propylthio)methyl]-2-oxo- 1,3-dioxolane (DPMOD)}

DMOD (8.0 mL, $69.3 \mathrm{mmol}), 1$-propanethiol $(6.28 \mathrm{~mL}$, $69.3 \mathrm{mmol}$ ) and DMPA (532.8 $\mathrm{mg}, 2,079 \mathrm{mmol})$ were transferred into the flask with a magnetic stirrer under nitrogen atmosphere and irradiated for $1 \mathrm{~h}$ by $365 \mathrm{~nm}$ UV lamp at room temperature. The crude product was purified by chromatography on a silica gel column with mixed solvent of THF/hexane=1/20. Yield 95\%. ${ }^{1} \mathrm{H}$ NMR $(400 \mathrm{MHz}$, DMSO- $\left.d_{6}\right) \delta: 4.59(\mathrm{t}, J=6.6 \mathrm{~Hz}, 1 \mathrm{H}), 2.85(\mathrm{~d}, J=6.6 \mathrm{~Hz}$, $2 \mathrm{H}), 2.58(\mathrm{td}, J=7.2,0.8 \mathrm{~Hz}, 2 \mathrm{H}), 1.62-1.51(\mathrm{~m}, 2 \mathrm{H}), 1.49$ (s, 3H), $1.35(\mathrm{~s}, 3 \mathrm{H}), 0.94(\mathrm{t}, J=7.3 \mathrm{~Hz}, 3 \mathrm{H}) ;{ }^{13} \mathrm{C}$ NMR $(101$ $\left.\mathrm{MHz}, \mathrm{DMSO}-d_{6}\right) \delta$ : $153.09,84.12,83.80,54.81,39.48$, $33.82,29.83,25.82,22.29,20.70,13.10$.

\section{The ring-opening addition of DPMOD with amines}

Take the reaction of DPMOD with butylamine as an example, the reaction was carried out in a Schlenk flask under a nitrogen atmosphere at given temperature, ethanol or TCM were used the solvents. After the reaction, the solvent was removed by vacuum distillation at $30{ }^{\circ} \mathrm{C}$. The conversion of DPMOD was determined by the ${ }^{1} \mathrm{H}$ NMR spectra of the crude product. The regioselectivity of DPMOD with butylamine was determined by ${ }^{1} \mathrm{H}\left({ }^{13} \mathrm{C}\right) \mathrm{NMR}$ and ${ }^{13} \mathrm{C}$-DEPT 135 spectra. Yield $95 \%$. ${ }^{1} \mathrm{H}$ NMR $(400 \mathrm{MHz}$, DMSO- $\left.d_{6}\right) \delta: 4.62(\mathrm{dd}, J=10.5,2.1 \mathrm{~Hz}, 1 \mathrm{H}), 3.02-2.94(\mathrm{~m}$, 2H), 2.89 (dd, $J=14.0,2.1 \mathrm{~Hz}, 1 \mathrm{H}), 2.55-2.39(\mathrm{~m}, 3 \mathrm{H})$, $1.52(\mathrm{dd}, J=7.3,2.2 \mathrm{~Hz}, 2 \mathrm{H}), 1.43-1.33(\mathrm{~m}, 2 \mathrm{H}), 1.33-$ $1.24(\mathrm{~m}, 2 \mathrm{H}), 1.05(\mathrm{~d}, J=10.6 \mathrm{~Hz}, 6 \mathrm{H}), 0.92(\mathrm{t}, J=7.3 \mathrm{~Hz}$, $3 \mathrm{H}), 0.86(\mathrm{t}, J=7.2 \mathrm{~Hz}, 3 \mathrm{H}) ;{ }^{13} \mathrm{C}$ NMR $\left(101 \mathrm{MHz}\right.$, DMSO- $\left.d_{6}\right)$ $\delta: 156.21,77.16,70.71,39.03,33.22,31.55,31.27,27.21$, $24.06,22.12,19.26,13.59,13.16$. IR $v_{\max }: 3460,3348$, 2958, 2926, 2868, 1700, 1518, 1248, $1062 \mathrm{~cm}^{-1}$. The reaction data of DPMOD with various amines (1-15) can be found in the supporting information part.

\section{Results and Discussion}

Initially, DMOD was synthesized from the direct coupling reaction of propargyl alcohol with $\mathrm{CO}_{2}$ using tributylphosphine as the catalyst [Scheme 2 , step (i)]. ${ }^{[34,43]}$ The reaction was carried out with a $\mathrm{CO}_{2}$ pressure of $5.0 \mathrm{MPa}$ at $100{ }^{\circ} \mathrm{C}$ for $8 \mathrm{~h}$. The crude product was then purified by vacuum distillation at $120^{\circ} \mathrm{C}$ to obtain a crystal with a purity of $>99 \%$, revealed by GC-MS spectra (Figure S1). The molecular structure of DMOD was also confirmed by the ${ }^{1} \mathrm{H}$ NMR spectrum with the characteristic chemical shifts of the double bond at 4.31 and $4.76 \mathrm{ppm}$ (Figure S2). Afterwards, the ultraviolet (UV) light-induced thiol-ene click reaction $^{[44-51]}$ of DMOD with 1-propanethiol was performed using 2,2-dimethoxy-2-phenylacetophenone (DMPA) as a free radical generator at room temperature, afforded 4,4dimethyl-5-[(propylthio)methyl]-2-oxo-1,3-dioxolane (DPMOD) within $1.0 \mathrm{~h}$. After the purification through a silica gel column chromatography eluted by the mixed THF/hexane (volume ratio: $1 / 20$ ) solution, a pure DPMOD was obtained. The molecular structure of DPMOD was confirmed by the 


\section{General Chemistry}

${ }^{1} \mathrm{H}$ NMR and ${ }^{13} \mathrm{C}$ NMR spectra (Figure S3). The integral area ratio of the protons $\mathrm{d}(2.85 \mathrm{ppm})$ to $\mathrm{c}(4.59 \mathrm{ppm})$ was 2.01/1.00 (see curve 1 in Figure S3), suggesting that 1-propanethiol was exclusively added to the terminated $\mathrm{CH}_{2}$ site of DMOD, ${ }^{[46]}$ which was a completely regioselective reaction.

Scheme 2 The regioselective synthesis of $\mathrm{N}$-alkyl carbamates. (i) Synthesis of DMOD, (ii) thiol-ene click reaction, and (iii) ring-opening addition of DPMOD with butylamine.

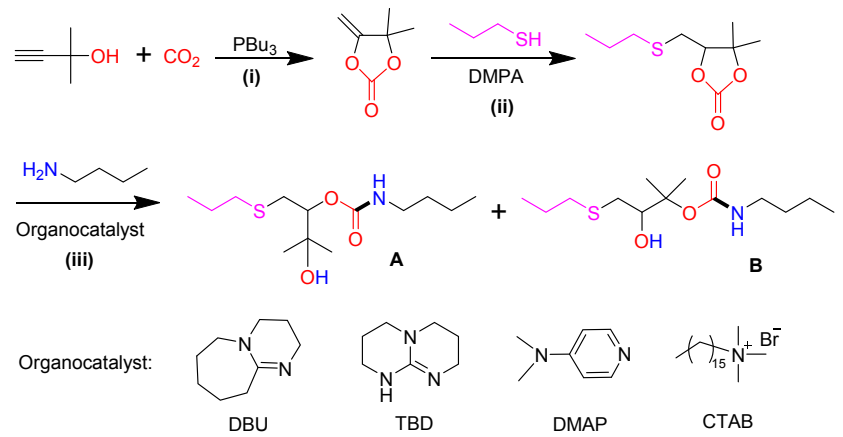

With DPMOD in hand, the ring-opening addition of DPMOD with butylamine was investigated. For this reaction, two regioisomers, i.e., 3-hydroxy-3-methyl-1-(propylthio)butan-2-yl butylcarbamate (A) and 3-hydroxy-2methyl-4-(propylthio)butan-2-yl butylcarbamate (B) would be produced, as depicted in Scheme $2 .^{[13,52,23]}$ In order to elaborate the regioselectivity of this reaction clearly, we defined firstly the method for calculating the regioselectivity based on the NMR results of the final products, using the product of Entry 1 in Table 1 as an example, as shown in Figures S4 and S5. Two kinds of protons (a and $\mathbf{b}$ ) linked to the tertiary carbon were clearly observed at 3.82 and 4.52-4.70 ppm that are two separated peaks (see curve 1 in Figure S4), represented the isomers $\mathbf{A}$ and $\mathbf{B}$, respectively. The A/B molar ratio was estimated to be $74: 26$ based on the integral area ratio of two peaks. Correspondingly, two sets of the resonance peaks at 77.1 (70.7) and 80.6 (74.7) ppm, which could be ascribed to the isomers $\mathbf{A}$ and $\mathbf{B}$, respectively, were accurately located by combining ${ }^{13} \mathrm{C}$ NMR and ${ }^{13} \mathrm{C}$-DEPT 135 techniques (Figures S5 and S8). Thus, the regioselectivity of the DPMOD/ amine reaction could be calculated based on the ${ }^{1} \mathrm{H}$ NMR spectra.

The effect of the types of organocatalysts on the ringopening addition of DPMOD with butylamine with the molar ratio of 1.0 was studied, as summarized in Table 1 (Entries 1-5). In the absence of the catalyst, such ring-opening addition presented low regioselectivity even that DPMOD had three substituents (Entry 1 in Table 1). The use of DMAP and CTAB as the catalysts resulted in slightly improved conversion of DPMOD (33.5 and $27.5 \%$ respectively) but similar A/B molar ratios with that of the products of entry 1 in Table 1 . When DBU was used for the reaction, the conversion of DPMOD and the $A / B$ molar ratio were sharply improved to $78.8 \%$ and $82 / 18$, respectively (Entry 4 , Table 1). The employment of TBD led to a higher regioselectivity for producing A (A/B molar ratio: 94/6) but a slightly low conversion of DPMOD (73.3\%, Entry 5 in Table 1). Clearly, strong organic bases had higher activity and selectivity towards the ring-opening addition of DPMOD with butylamine.

The DPMOD conversion and the selectivity to produce
A could be dramatically improved by either using the ethanol or increasing the amounts of butylamine. For example, when TCM was replaced by ethanol, the DPMOD conversion increased from $73.3 \%$ to $87.8 \%$, and the A/B molar ratio increased from $94: 6$ to $97: 3$ in the presence of $5 \mathrm{~mol} \%$ TBD (Entries 5-6 in Table 1). Owing to the high reactive activity of butylamine unlike aniline, $5 \mathrm{~mol} \%$ TBD is enough for the ring-opening reaction. Increasing the feeding ratio of butylamine/DPMOD to 1.5 in ethanol led to a dramatic improvement of the DPMOD conversion to $100 \%$ at $30{ }^{\circ} \mathrm{C}$ within a shorter reaction time $(12 \mathrm{~h})$, and the selectivity of producing $\mathrm{A}$ reached to $>99 \%(100 \%)$ determined by ${ }^{1} \mathrm{H}$ NMR $\left[{ }^{13} \mathrm{C}\left({ }^{13} \mathrm{C}\right.\right.$-DEPT 135)] NMR spectra, as shown in Entry 7 (Table 1, Figure S9). Under the circumstance of excess butylamine in ethanol, increasing the reaction temperatures to 50,70 and $100{ }^{\circ} \mathrm{C}$, DPMOD could be completely consumed within a shorter reaction time (4-8 h, Figures S4-S5 and S7-S8), while the regioselectivity for producing A was nearly unvaried, as Entries 8-10 in Table 1 , only a small portion of B (3\%) was produced at 70 and $100{ }^{\circ} \mathrm{C}$. Of interest, even TCM used as the solvent, DPMOD could also be completely consumed with $100 \%$ selectivity to $\mathbf{A}$ at $50{ }^{\circ} \mathrm{C}$ within $8 \mathrm{~h}$ (Entry 11 , Table 1). Thus, it is the key to improving the DPMOD conversion and A/B selectivity using excess of butylamine in the presence of TBD. When DBU was used as the catalyst, the DPMOD/ butylamine addition reaction in ethanol (Entries 12-15, Table 1) showed slight lower DPMOD and A/B selectivity than those of the TBD catalysis under the same reaction conditions. Based on the above results, we can conclude that the use of TBD, excess of butylamine and ethanol are favorable to achieve selective production of tertiary $\beta$-hydroxyl $N$-alkyl carbamates (A) with $100 \%$ conversion of DPMOD.

Unlike what was seen for the regioselective aminolysis of epoxide-derived disubstituted cyclic carbonates using $20 \mathrm{~mol} \%$ of TBD and excess amounts of amine (2.0-6.0 equiv.), ${ }^{[42]}$ small quantity of organocatalyst (5 mol\%) and $1.0-1.5$ equiv. amine were used in our system. Moreover, the use of ethanol could assist the regioselective reaction of DPMOD with butylamine under the low reaction temperature of $30{ }^{\circ} \mathrm{C}$ (Entries 5-6 in Table 1).

The hydrogen bonding interaction among butylamine, TBD and DPMOD and the proton migration ${ }^{[53,54]}$ are proposed to be responsible for the highly regioselective reaction, similar to Kleij's proposal ${ }^{[42,53]}$ and as depicted in Scheme 3. Firstly, the possible intermediates $1 \mathrm{~A} / 1 \mathrm{~B}$ and 2A/2B existed because of appearance of a tetrahedral geometry after butylamine attacked the quaternary carbon of the carbonate and $\mathrm{N}-\mathrm{H} \cdots \mathrm{N}$ hydrogen bond was formed. Secondly, considering the energy barrier and the inversion from $\mathbf{2 A}$ to $\mathbf{3 B}$, the route from $\mathbf{2 A}$ to $\mathbf{3 A}$ is easier and more reasonable. Thirdly, owing to the stronger ability of electron donating for the two methyl groups, the oxygen atom next to the two methyl groups have stronger electronegativity to combine with $\mathrm{N}-\mathrm{H}$ of the TBD to produce the $3 \mathrm{~A}$ rather than 3B. Finally, the oxygen anion of $4 A$ is more unstable so that it can capture proton easily, which was strongly supported by the fact that the protic solvent favored the selective production of $\mathbf{A}$.

We also examined the ring-opening addition of DPMOD with various amines, including aliphatic primary and secondary amines, aromatic primary amines and guanamine in ethanol at $50{ }^{\circ} \mathrm{C}$ for $8 \mathrm{~h}$ in the presence of TBD $(5.0 \mathrm{~mol} \%)$, as collected in Table 2. When the aliphatic primary amines (1-3, Table 2) were used, 
Table 1 Organocatalyzed ring-opening addition of DPMOD with butylamine in various reaction conditions ${ }^{a}$

\begin{tabular}{cccccccc}
\hline Entry & DPMOD:butylamine & $T /{ }^{\circ} \mathrm{C}$ & Solv. & $t / h$ & Cat. & Conv. $/ \%^{b}$ & A:B $^{c}$ \\
\hline 1 & $1: 1$ & 30 & TCM & 30 & None & 23.4 & $74: 26$ \\
2 & $1: 1$ & 30 & TCM & 30 & DMAP & 33.5 & $74: 26$ \\
3 & $1: 1$ & 30 & TCM & 30 & CTAB & 27.5 & $70: 30$ \\
4 & $1: 1$ & 30 & TCM & 30 & DBU & 78.8 & $82: 18$ \\
5 & $1: 1$ & 30 & TCM & 30 & TBD & 73.3 & $94: 6$ \\
6 & $1: 1$ & 30 & EtOH & 30 & TBD & 87.8 & $97: 3$ \\
7 & $1: 1.5$ & 30 & EtOH & 12 & TBD & 100 & $>99(100)^{e}$ \\
8 & $1: 1.5$ & 50 & EtOH & 8 & TBD & 100 & $>99(100)^{e}$ \\
9 & $1: 1.5$ & 70 & EtOH & 4 & TBD & 100 & $97: 3$ \\
$10^{d}$ & $1: 1.5$ & 100 & EtOH & 4 & TBD & 100 & $97: 3$ \\
11 & $1: 1.5$ & 50 & TCM & 8 & TBD & 100 & $>99(100)^{e}$ \\
12 & $1: 1.5$ & 30 & EtOH & 24 & DBU & 98.8 & $83: 17$ \\
13 & $1: 1.5$ & 50 & EtOH & 8 & DBU & 98.5 & $88: 12$ \\
14 & $1: 1.5$ & 70 & EtOH & 4 & DBU & 99 & $94: 6$ \\
$15^{\text {d }}$ & $1: 1.5$ & 100 & EtOH & 4 & DBU & 99 & $97: 3$ \\
\hline
\end{tabular}

${ }^{a}$ Reaction conditions: DPMOD $(0.1 \mathrm{~mL}, 0.588 \mathrm{mmol})$, catalyst loading: $5 \mathrm{~mol} \%$ related to DPMOD, solvent: $0.2 \mathrm{~mL}, \mathrm{~N}_{2}$ atmosphere. TCM: chloroform, EtOH: ethanol. ${ }^{b}$ Determined by ${ }^{1} \mathrm{H}$ NMR spectra of the crude product, Conv. $=\left[\left(A_{4.70-4.52}-A_{2.58} / 2\right) / A_{4.70-4.52}\right]^{*} 100 \%$. ${ }^{c}$ Determined by ${ }^{1} \mathrm{H}$ NMR of the crude product, product ratio $\mathrm{A}: \mathrm{B}=\left(A_{4.70-4.52}-A_{2.58} / 2\right): A_{3.82} .{ }^{d}$ In the pressure glass bottle. ${ }^{e}$ The value of 100 was from ${ }^{13} \mathrm{C}$-DEPT 135 and ${ }^{13} \mathrm{C}$ NMR spectra.

Scheme 3 Proposed mechanism for the TBD-catalyzed ring-opening addition to produce $\mathbf{A}$ and $\mathbf{B}$.

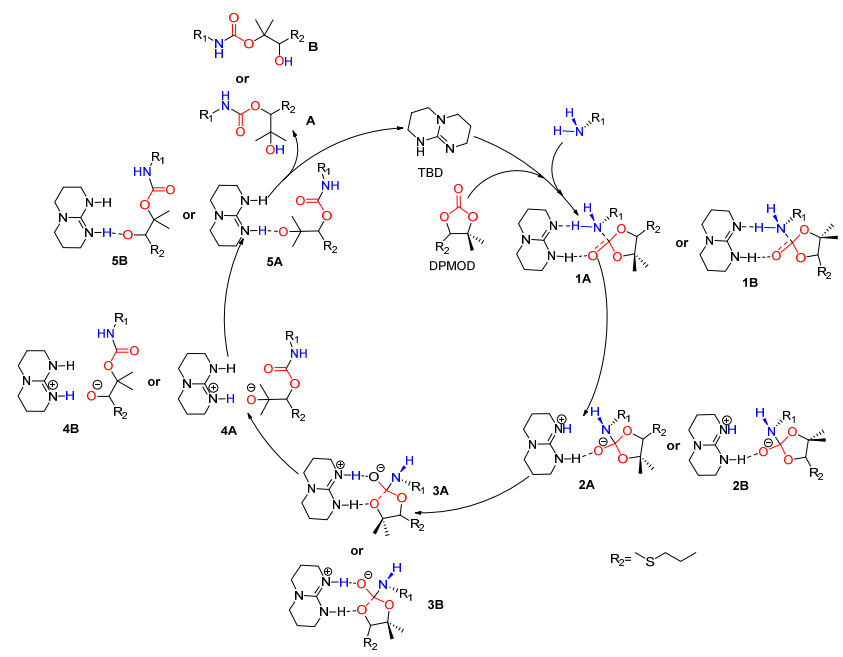

DPMOD was completely consumed and the A/B molar ratios were $97: 3$ for 1 and 3 , and $>99$ for 2 . Of special, the reaction of 2 with DPMOD afforded $29.6 \%$ of 2-oxazolidone, which was derived from the back-biting reaction of $\mathbf{A}$ (Scheme 4). ${ }^{[55]}$ As compared 4 with 3, long alkyl chain between two amino groups caused relatively low DPMOD conversion (83.4\%) and A/B selecttivity (95:5). Furthermore, isophorondiamine (5) has two amino groups with unequal reactivity, presented a further decreased conversion of DPMOD $(71 \%)$ and A/B selectivity (85:15). However, 1,2-diamino-cyclo-hexane (6) with two amino groups with equal reactivity, had excellent A/B selectivity of $>99$, but the DPMOD conversion was $70 \%$ and similar to that of the reaction of DPMOD with $\mathbf{5}$. As a result, big steric hindrance of the primary amine was beneficial to the selective
Table 2 TBD-catalyzed reaction of DPMOD with various amines for producing sulfur-containing $N$-alkyl carbamates ${ }^{a}$

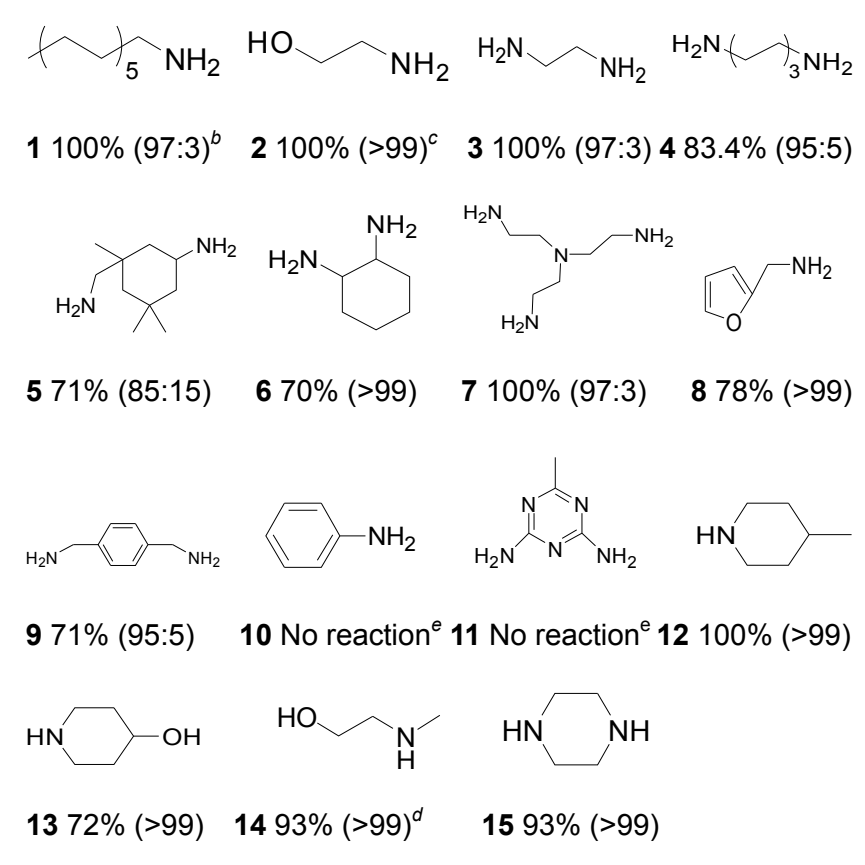

\footnotetext{
${ }^{a}$ Reaction conditions: DPMOD $(0.1 \mathrm{~mL}, 0.588 \mathrm{mmol})$, the molar ratio of the amino group $(\mathrm{N}-\mathrm{H})$ to DPMOD was 1.5 , TBD: $5 \mathrm{~mol} \%$ related to DPMOD, ethanol: $0.2 \mathrm{~mL}, \mathrm{~N}_{2}$ atmosphere. The DPMOD conversion and regioselectivity were determined by ${ }^{1} \mathrm{H}\left({ }^{13} \mathrm{C}\right)$ NMR spectra of the crude products. " 1 " refers to the serial number of amine, "100\% (97:3)" refers to the conversion of DPMOD (the molar ratio of $\mathbf{A} / \mathbf{B}$ ). ${ }^{c} 29.6 \%$ 2-oxazolidone was produced. ${ }^{d} 52.6 \%$ 3-methyl-2-oxazolidone produced. ${ }^{e}$ TBD: $30 \mathrm{~mol} \%$ related to DPMOD, $75^{\circ} \mathrm{C}, 24 \mathrm{~h}$.
} 
Scheme 4 The back-biting reaction of $\mathbf{A}$ to produce the by-product of oxazolidone.

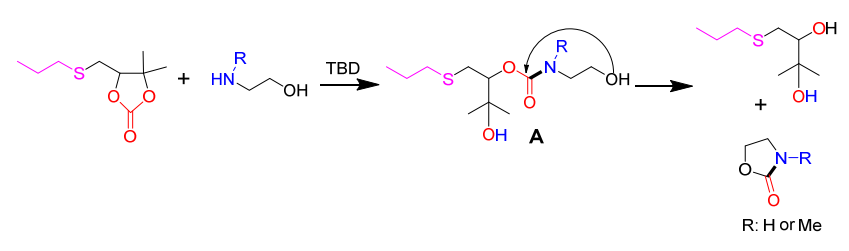

production of A, while the DPMOD conversion was weakened. In addition, tris(2-aminoethyl)amine (7) presented the same DPMOD conversion and $A / B$ selectivity with 3 . Therefore, both $\mathbf{3}$ and $\mathbf{7}$ could be potentially applied for regioselective synthesis of PUs.

Aryl-substituted aliphatic primary amines showed low reactivity towards the DPMOD/amine reaction. When furfurylamine (8) and $p$-xylylenediamine (9) were employed, the DPMOD conversions reached to $78 \%$ and $71 \%$, respectively. However, the regioselectivity to produce $\mathbf{A}$ was $>99 \%$ and $95 \%$, respectively. Aniline (10) and acetoguanamine (11), which were aromatic, could not react with DPMOD under the same reaction conditions.

The results of the ring-opening addition of DPMOD with secondary amines 12-15 are listed in Table 2. All the reactions showed $>99 \%$ production of regioisomer $\mathbf{A}$, which indicated that the steric hindrance of these secondary amines is favourable to the regioselective ring-opening of DPMOD. Compared with 4-methylpiperidine (12), the use of 13 caused lower conversion of DPMOD (72\%), while 12 led to a $100 \%$ conversion of DPMOD. It is reasonable that the methyl group of $\mathbf{1 2}$ was more electron-donating than the hydroxyl group of 13 and thus improved the reactivity of 12 towards DPMOD. 2-(Methylamino)ethanol (14) with less steric hindrance than 13, could also react with DPMOD with $99 \%$ regioselectivity for producing A. However, $52.6 \%$ of 3-methyl-2-oxazolidone was produced via the same route as the reaction of DPMOD with 2 , as shown in Scheme 4. Obviously, the reaction of the aminoethanol with DPMOD produced oxazolidone inevitably, which is conversely a useful method to synthesize heterocyclic compound from $\mathrm{CO}_{2}{ }^{[55-57]}$ In addition, piperazine (15) could react with DPMOD with 93\% DPMOD conversion and $>99 \%$ regioselectivity, which could be potentially migrated to the synthesis of PUs.

\section{Conclusions}

In summary, we reported a highly efficient and regioselective synthesis of sulfur-containing $\mathrm{N}$-alkyl carbamate that was originated from propargyl alcohol, $\mathrm{CO}_{2}$ and amine. Ring-opening addition of DPMOD with various amines were carried out using the organocatalysts, afforded tertiary $\beta$-hydroxyl $N$-alkyl carbamates (A) with DPMOD conversion of up to $100 \%$ and regioselectivity of $100 \%$. TBD was shown to be a very active organocatalyst for the regioselective formation of $\beta$-hydroxyl $N$-alkyl carbamate. Due to abundant mercapto compounds and amines, considerable amounts of sulfur-containing $\mathrm{N}$-alkyl carbamates could be synthesized by this method, greatly broadening their practical applications. Of importance, propargyl alcohol and $\mathrm{CO}_{2}$ were used as the basic substrates during the synthetic process, which is petroleum- independent, eco-friendly and sustainable. Such regioselective product, $\beta$-hydroxyl $N$-alkyl carbamate could be used as a platform compound for potential synthesis.

\section{Acknowledgement}

We gratefully acknowledge the financial support of the National Science Foundation of China (No. 21474083) and the financial support of the Distinguished Young Investigator Fund of Zhejiang Province (No. LR16B040001).

\section{Supporting Information}

Supporting information for this article is available on the WWW under www.genchemistry.org/EN/10.21127/yaoyigc201 80007.

\section{References}

[1] Qin, A.; Lam, J. W. Y.; Tang, B. Z. Prog. Polym. Sci. 2012, 37, 182.

[2] Ackermann, L. Acc. Chem. Res. 2014, 47, 281.

[3] Morten, M.; Christian Wenzel, T. E. Chem. Rev. 2008, 108, 2952.

[4] Cokoja, M.; Bruckmeier, C.; Rieger, B.; Herrmann, W. A.; Kühn, F. E. Angew. Chem. Int. Ed. 2011, 50, 8510.

[5] Müller, K.; Mokrushina, L.; Arlt, W. Chem. Ing. Tech. 2014, 86, 497.

[6] Luo, M.; Li, Y.; Zhang, Y. Y.; Zhang, X. H. Polymer 2016, 82, 406.

[7] Chen, K.; Shi, G.; Dao, R.; Mei, K.; Zhou, X.; Li, H.; Wang, C. Chem. Commun. 2016, 52, 7830.

[8] Qiu, J.; Zhao, Y.; Li, Z.; Wang, H.; Fan, M.; Wang, J. ChemSusChem 2017, 10, 1120.

[9] Martín, C.; Fiorani, G.; Kleij, A. W. ACS Catal. 2015, 5, 1353.

[10] Comerford, J. W.; Ingram, I. D. V.; Michael, N.; Xiao, W. Green Chem. 2014, 17, 1966.

[11] Cokoja, M.; Wilhelm, M. E.; Anthofer, M. H.; Herrmann, W. A.; Kühn, F. E. ChemSusChem 2015, 8, 2436.

[12] Zou, B.; Hu, C. Chin. J. Chem. 2017, 35, 541.

[13] Maisonneuve, L.; Lamarzelle, O.; Rix, E.; Grau, E.; Cramail, H. Chem. Rev. 2015, 115, 12407.

[14] Figovsky, O.; Leykin, A.; Shapovalov, L.; Birukova, O.; Potashnikova, R. PU Mag. Int. 2013, 30, 256.

[15] Lee, S. H.; Cyriac, A.; Jeon, J. Y.; Lee, B. Y. Polym. Chem. 2012, 3 , 1215.

[16] Kenar, J. A.; Tevis, I. D. Eur. J. Lipid Sci. Technol. 2005, 107, 135.

[17] Wei, R. J.; Zhang, X. H.; Du, B. Y.; Fan, Z. Q.; Qi, G. R. RSC Adv. 2013, 379, 38 .

[18] Wei, R. J.; Zhang, X. H.; Du, B. Y.; Fan, Z. Q.; Qi, G. R. RSC Adv. 2013, 3, 17307.

[19] Ma, R.; He, L. N.; Zhou, Y. B. Green Chem. 2015, 18, 226

[20] Iwasaki, T.; Kihara, N.; Endo, T. Bull. Chem. Soc. Jpn. 2000, 73, 713.

[21] Steblyanko, A.; Choi, W.; Sanda, F.; Endo, T. J. Polym. Sci., Part A: Polym. Chem. 2000, 38, 2375.

[22] Ochiai, B.; Satoh, Y.; Endo, T. Green Chem. 2005, 7, 765.

[23] Tomita, H.; Sanda, F.; Endo, T. J. Polym. Sci., Part A: Polym. Chem. 2001, 39, 851.

[24] Tomita, H.; Sanda, F.; Endo, T. J. Polym. Sci., Part A: Polym. Chem. 2001, 39, 3678.

[25] Griebel, J. J.; Namnabat, S.; Kim, E. T.; Himmelhuber, R.; Moronta, D. H.; Chung, W. J.; Simmonds, A. G.; Kim, K. J.; Laan, J. V. D.; Nguyen, N. A. Adv. Mater. 2014, 26, 3014.

[26] Rafikov, S. R. Polym. Sci. U.S.S.R 1979, 21, 2780.

[27] Kausar, A.; Zulfiqar, S.; Sarwar, M. I. Polym. Rev. 2014, 54, 185.

[28] Yamada, W.; Sugawara, Y.; Cheng, H. M.; Ikeno, T.; Yamada, T. Cheminform 2007, 38, 2604.

[29] Inoue, Y.; Ishikawa, J.; Taniguchi, M.; Hashimoto, H. Bull. Chem. Soc. Jpn. 1987, 60, 1204.

[30] Iritani, K.; Yanagihara, N.; Utimoto, K. J. Org. Chem. 1986, 51, 5499.

[31] Tang, X.; Qi, C.; He, H.; Jiang, H.; Ren, Y.; Yuan, G. Adv. Synth. Catal. 2013, 355, 2019.

[32] Yoshida, M.; Fujita, M.; Ishii, T.; Ihara, M. J. Am. Chem. Soc. 2003 
$125,4874$.

[33] Boyaval, A.; Méreau, R.; Grignard, B.; Detrembleur, C.; Jerome, C.; Tassaing, T. ChemSusChem 2017, 10, 1241.

[34] Fournier, J.; Bruneau, C.; Dixneuf, P. H. Tetrahedron Lett. 1989, 30, 3981.

[35] Bruneau, C.; Dixneuf, P. H. J. Mol. Catal. 1992, 74, 97.

[36] Vani, P. V.; Chida, A. S.; Srinivasan, R.; Chandrasekharam, M.; Singh, A. K. Synth. Commun. 2001, 31, 219.

[37] Song, Q.-W.; Yu, B.; Li, X.-D.; Ma, R.; Diao, Z.-F.; Li, R.-G.; Li, W.; He, L.-N. Green Chem. 2014, 16, 1633.

[38] Jerome, M.; Krchma, I. J. US1779676, 1930.

[39] Titov, I. Y.; Chernysheva, N. B.; Chudinov, Y. B.; Bogolyubov, A. A.; Semenov, V. V. Cheminform 2006, 55, 569.

[40] Shi, M.; Shen, Y. M.; Chen, Y. J. Heterocycles 2002, 57, 245.

[41] Gennen, S.; Grignard, B.; Tassaing, T.; Jerome, C.; Detrembleur, C. Angew. Chem. Int. Ed. 2017, 56, 10394.

[42] Sopeña, S.; Laserna, V.; Guo, W.; Martin, E.; Escudero-Adán, E. C.; Kleij, A. W. Adv. Synth. Catal. 2016, 358, 2172.

[43] Joumier, J. M.; Fournier, J.; Bruneau, C.; Dixneuf, P. H. J. Chem. Soc., Perkin Trans. 1 1992, 23, 3271.

[44] Hoyle, C. E.; Bowman, C. N. Angew. Chem. Int. Ed. 2010, 49, 1540.

[45] Hoyle, C. E.; Lee, T. Y.; Roper, T. J. Polym. Sci., Part A: Polym. Chem. 2004, 42, 5301.

[46] Lowe, A. B. Polym. Chem. 2010, 1, 17.

[47] Kade, M. J.; Burke, D. J.; Hawker, C. J. J. Polym. Sci., Part A:
Polym. Chem. 2010, 48, 743.

[48] Liu, Z.; Ou, J.; Lin, H.; Liu, Z.; Wang, H.; Dong, J.; Zou, H. Chem. Commun. 2014, 50, 9288

[49] Rix, E.; Grau, E.; Chollet, G.; Cramail, H. Eur. Polym. J. 2016, 84, 863.

[50] Benyahya, S.; Desroches, M.; Auvergne, R.; Carlotti, S.; Caillol, S.; Boutevin, B. Polym. Chem. 2011, 2, 2661.

[51] Tomita, H.; Sanda, F.; Endo, T. J. Polym. Sci., Part A: Polym. Chem. 2001, 39, 860 .

[52] Lombardo, V. M.; Dhulst, E. A.; Leitsch, E. K.; Wilmot, N.; Heath, W. H.; Gies, A. P.; Miller, M. D.; Torkelson, J. M.; Scheidt, K. A. Eur. J. Org. Chem. 2015, 46, 2791.

[53] Guo, W.; Gónzalez-Fabra, J.; Bandeira, N. A. G.; Bo, C.; Kleij, A. W. Angew. Chem. Int. Ed. 2015, 54, 11686.

[54] Venkataraman, S.; Ng, V. W. L.; Coady, D. J.; Horn, H. W.; Jones, G. O.; Fung, T. S.; Sardon, H.; Waymouth, R. M.; Hedrick, J. L.; Yang, Y. Y. J. Am. Chem. Soc. 2015, 137, 13851.

[55] Pulla, S.; Unnikrishnan, V.; Ramidi, P.; Sullivan, S. Z.; Ghosh, A.; Dallas, J. L.; Munshi, P. J. Mol. Catal. A-Chem. 2011, 338, 33.

[56] Cwik, A.; Fuchs, A.; Hell, Z.; Bojtos, I.; Halmai, D.; Bombicz, P. Org. Biomol. Chem. 2005, 3, 967.

[57] Li, P.; Yuan, X.; Wang, S.; Lu, S. Tetrahedron 2007, 63, 12419.

Received March 14, 2018 Accepted April 18, 2018 